\title{
The Empirical Research on the Relationship between Price Fluctuation and Urban-rural Income Gap
}

\author{
Yaxu Li $i^{1, a}$, Shujun Ye \\ ${ }^{1}$ School of Economics and Management, Beijing Jiaotong University, Beijing 100044, China \\ ${ }^{2}$ School of Economics and Management, Beijing Jiaotong University, Beijing 100044, China \\ aliyaxubjtu@163.com, bshjye@bjtu.edu.cn
}

\begin{abstract}
Keywords: Price Fluctuation, Urban-rural Income Gap, Granger causality, VAR model
Abstract. This study analyzes the relationship between price fluctuation and urban-rural income gap by the granger causality test, vector auto-regressive(VAR) model, impulse response function and variance decomposition. The results of the granger causality test indicate that there is a one-way causal relationship between price fluctuation and urban-rural income gap. Price fluctuation is the granger cause of the urban-rural income gap. There is a negative impact of price fluctuation on the urban-rural income gap from the result of impulse response function and the contribution rate of the price fluctuation to urban-rural income gap is about $25 \%$. At the end of the study, the reason for these results is explained.
\end{abstract}

\section{Introduction}

Urban-rural income gap is a problem we have to confront with during the development of dual economy in China. In theory, price fluctuation is closely related to the residents' income and consumption level. On the one hand, due to the income redistributive effect of inflation, the impact of price fluctuation on different income groups are different. High-income groups have low Engel's Coefficient and generally have higher education and financial management ability to promptly adjust their asset allocation by buying gold, stocks and real estate to hedge or even add value to resist inflation. Relatively, low-income groups have higher Engel's coefficient and their income is almost all used for consumption [1,2]. Moreover, low-income groups mostly play the role of creditors, while most of high-income groups are debtors. Inflation will transfer the wealth of creditors to the debtors. To sum up, in the case of inflation, the poor lose wealth, while the rich can accumulate wealth. Therefore, inflation makes urban-rural income gap widen. On the other hand, due to the diminishing marginal propensity to consume, high-income groups have high consumption ability but low marginal propensity to consume, to which low- income groups are opposite [3]. Therefore, urban-rural income gap makes aggregate demand decline, leading to the decline in inflation.

At present, There is little research on the relationship between price fluctuation and urban-rural income gap. Deng and Li (2006) make an empirical test on the relationship between residents' income gap and inflation by AEG co integration test, whose result indicates that there is a long-term equilibrium relationship between income gap and inflation. Based on the data from 1978 to 2010, Ji and Yu (2013) study the relationship by granger causality test, and conclude that there is a two-way relationship between the two factors. Based on the structural theory, Dong and $\mathrm{Wu}(2013)$ find that the improvement of income gap, caused by the improvement of rural household income, has little effect on the fluctuation of inflation. Zhu(2016) analyzes the impact of inflation on the income from the perspective of assets hedge and argues that inflation makes urban-rural income gap worse.

Most of the studies use granger causality test or co integration test to prove that there is a causal or long-term equilibrium relationship between price fluctuation and urban-rural income gap. Based on the VAR model, this study uses impulse response function to analyze the response of one variable to another variable and variance decomposition to quantitatively analyze the impact of the relationship between the variables. 


\section{Data description}

This study analyzes the relationship between price fluctuation and urban-rural income gap and applies analysis on annual data from 1978 to 2014, which is from China Statistical Yearbook. There is no uniform standard to distinguish between rising prices and falling prices. Drawing on the previous research, this study uses the following method to determine the level of price fluctuation. This study separates the long-term trend and short-term fluctuation of CPI time series by HP filter method, then we can obtain the level of price fluctuation. If VCPI is positive, it indicates the rise in prices. For the measurement of urban-rural income gap, most of the literature takes the ratio between urban and rural income as its measure. Considering the universality and data availability, this study uses the ratio between urban and rural income to measure urban-rural income gap [4]. The variables, corresponding abbreviations and measurement index are listed in Table 1.

Table 1. Variable description.

\begin{tabular}{lll}
\hline Variable & $\begin{array}{l}\text { Abbreviatio } \\
\mathrm{n}\end{array}$ & Measurement Index \\
\hline Price Fluctuation & VCPI & $\begin{array}{l}\text { CPI adjusted by HP filter method } \\
\text { Per capita disposable income of urban households/ Net } \\
\text { income of rural residents }\end{array}$ \\
\hline
\end{tabular}

\section{Empirical analysis}

3.1. Unit Root Test. This study uses Augmented Dickey-Fuller test(ADF) to test the stability of time series. The result of the test, showed in Table 2, indicates that all the variables are stationary and we can use the time series for further analysis.

Table 2. ADF test result.

\begin{tabular}{lllll}
\hline Variable & t-Statistic & 1\% level critical value & 5\% level critical value & 10\% level critical value \\
\hline Gap & -3.421771 & -4.243644 & -3.544284 & -3.204699 \\
VCPI & -5.354536 & -3.632900 & -2.948404 & -2.612874 \\
\hline
\end{tabular}

In the case of ADF test, the null hypothesis is non-stationary. Null hypothesis should be rejected when t-Statistic is less than the critical value. Therefore, the variables are stationary.

3.2. VAR model Estimation. The VAR model does not take the strict economics theory as the basis. The mutual relationship between variables can be reflected, as long as the relational variables are introduced into the model and the lag of variables is determined. According to the AIC and SIC information criterion, the appropriate lag order for granger causality test and VAR model is 2 . The model is estimated by the least square method and the following equations can be obtained.

$$
\begin{aligned}
& \mathrm{GAP}_{\mathrm{t}}=1.417 \mathrm{GAP}_{\mathrm{t}-1}-0.455 \mathrm{GAP}_{\mathrm{t}-2}-0.009 \mathrm{VCPI}_{\mathrm{t}-1}-0.005 \mathrm{VCPI}_{\mathrm{t}-2}+0.106 \\
& \mathrm{VCPI} \mathrm{t}_{\mathrm{t}}=3.436 \mathrm{GAP}_{\mathrm{t}-1}-2.541 \mathrm{GAP}_{\mathrm{t}-2}+0.626 \mathrm{VCPI}_{\mathrm{t}-1}-0.479 \mathrm{VCPI}_{\mathrm{t}-2}-2.412
\end{aligned}
$$

R-squared is 0.9626 and adjusted R-squared is 0.9576 . The overall goodness of fit is good, indicting that the result has strong explanatory power to the whole system.

3.3. Granger Causality Test. After estimating the dynamic relationship between the joint endogenous variables, this study tests the causal relationship between variables by granger causality test. In the case of time series, the granger causality between $\mathrm{Y}$ and $\mathrm{X}$ is defined as follows. If the variable $\mathrm{X}$ helps to explain the future change of the variable $\mathrm{Y}$, then it is considered that the variable $\mathrm{X}$ is the granger cause of the variable $\mathrm{Y}$. The results of the granger causality test are shown in Table 3. Table 3. Granger causality test result.

\begin{tabular}{llll}
\hline Null Hypothesis & F-Statistic & P-value & Lag \\
\hline VCPI does not Granger Cause GAP & 4.87192 & 0.0147 & 2 \\
GAP does not Granger Cause VCPI & 0.36366 & 0.6982 & 2 \\
\hline
\end{tabular}


We can reject the null hypothesis that VCPI does not granger cause GAP but we can't reject the null hypothesis that GAP does not granger cause VCPI. Therefore, there is a one-way causal relationship between price fluctuation and urban-rural income gap. Price fluctuation is the granger cause of the urban-rural income gap. How to affect each other between price fluctuation and urban-rural income gap has been analyzed in the introduction. The reason why urban-rural income gap is not the granger cause of price fluctuation may be that the government plays an important role. When there is a great gap among the citizens' income, the government may increase subsidies for low-income groups, which offsets the decline in inflation by lack of aggregate demand.

3.4. Impulse Response Function. Impulse response function describes the response of one variable to another variable. Therefore, we use impulse response function to further analyze the impact of price fluctuation on urban-rural income gap. It is essential to test the stability of VAR model before making impulse response analysis and variance decomposition.

Inverse Roots of AR Characteristic Polynomial

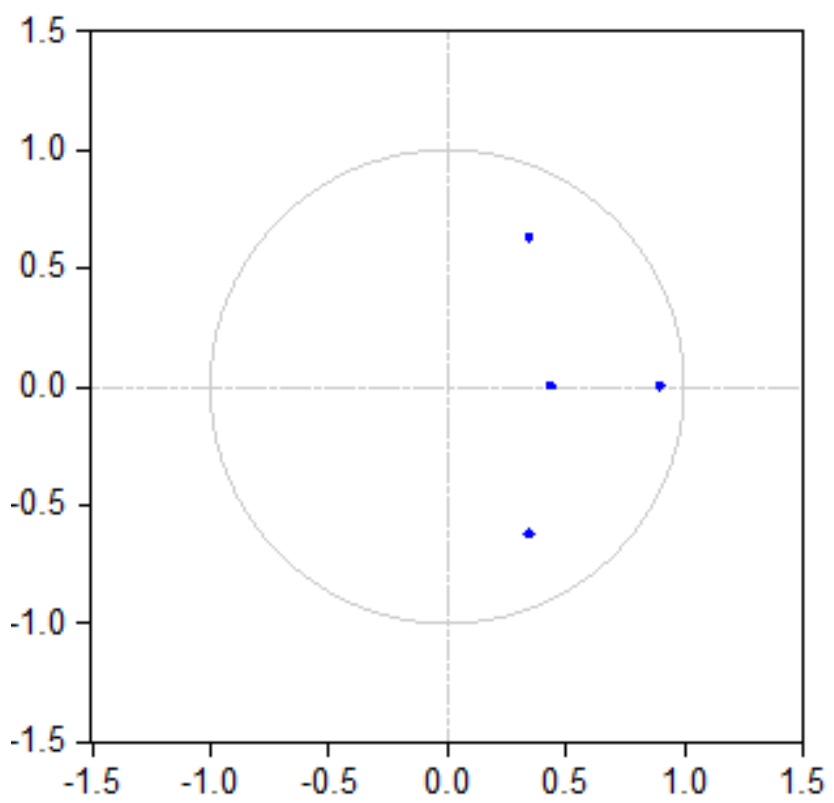

Fig. 1. Stability test of VAR model

Fig. 1 shows that the inverse roots of AR characteristic polynomial are all inside of the unit circle, indicating the VAR model is stable. Then we can analyze impulse response function and get the graph of impulse response function.

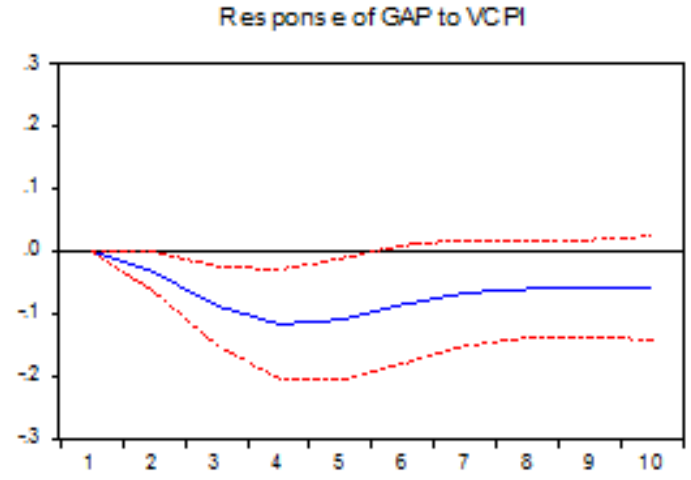

Fig. 2. Response of GAP to VCPI

Fig. 2 indicates that when price fluctuation is applied to one standard deviation innovation, the response of urban-rural income gap is negative. Rising prices will narrow the urban-rural income gap, which is opposite to the theoretical analysis in introduction. The reason may be that the government increases subsidies for low-income groups to protect them from the negative impacts of price fluctuation, which is consistent with the previous analysis in 3.3. 
3.5. Variance Decomposition. Variance decomposition can quantitatively describe the impact of price fluctuation on urban-rural income gap. The result of variance decomposition is shown in Table 4.

Table 4. Variance Decomposition of GAP.

\begin{tabular}{rccc}
\hline Period & S.E. & GAP & VCPI \\
\hline 1 & 0.099213 & 100.0000 & 0.000000 \\
2 & 0.179090 & 96.56808 & 3.431920 \\
3 & 0.257834 & 86.89225 & 13.10775 \\
4 & 0.325900 & 78.93120 & 21.06880 \\
5 & 0.374049 & 75.43980 & 24.56020 \\
6 & 0.405332 & 74.68471 & 25.31529 \\
7 & 0.427250 & 74.80110 & 25.19890 \\
8 & 0.444700 & 74.89932 & 25.10068 \\
9 & 0.459498 & 74.76776 & 25.23224 \\
10 & 0.471788 & 74.53262 & 25.46738 \\
\hline
\end{tabular}

Urban- rural income gap is only affected by its own fluctuation in the first period. In the second period, the impact of price fluctuation on urban- rural income gap begins to emerge and the contribution rate of the price fluctuation is gradually stabilized at $25 \%$.

\section{Conclusions}

This paper makes a theoretical analysis of the relationship between price fluctuation and urban- rural income gap at first, and then uses a variety of empirical methods, including granger causality test, impulse response function and variance decomposition, to test the relationship. The empirical results indicate that price fluctuation is the granger cause of the urban-rural income gap, while urban-rural income gap is not the granger cause of price fluctuation. Price fluctuation has a negative impact on urban- rural income gap and the contribution rate is about $25 \%$. This paper argues that the reason why the result is opposite to the theoretical analysis is that the government plays an important role. In the case of the rapid rise in prices and continued expansion of the income gap, government increases subsidies for low-income groups to protect their interests, which narrows the urban- rural income gap and offsets the decline in inflation by lack of aggregate demand. But the negative fact of price fluctuation on urban-rural income gap, relying on government subsidies, is unsustainable. Improving the rural residents' income by improving the price system of agricultural products and promoting the development of rural finance to increase the source of rural income is essential to sustainable development. At the same time, the price fluctuation should be controlled within a reasonable range.

\section{Acknowledgements}

This work was financially supported by the Shanghai Natural Science Foundation (0666666), Innovation Program of Shanghai Municipal Education Commission (060000) and Shanghai Leading Academic Discipline Project of Shanghai Municipal Education Commission (0555555).

\section{References}

[1] SH. Zhu. The influence of inflation on the urban-rural income gap from the perspective of asset value. Journal of Finance Economy(2016).

[2] Z.W. Dong. Research on the relationship between inflation and income distribution of urban and rural residents. Journal of Agrotechnical Economics(2013).

[3] X.Y. Deng, S.W. Li. The relationship between resident's income gap and inflation. Journal of China Economist(2006).

[4] L. Ji, M. Yu. Empirical test of the impact of price fluctuation on the urban-rural income gap. Journal of Statistics and Decision(2013). 